\title{
Characterisation, Recovery and Activity of Hydrophobic Compounds in Norway Spruce Log Soaking Pit Water: Could they be Used in Wood Preservative Formulations?
}

\author{
Aitor Barbero-López ${ }^{1}$ (1) $\cdot$ Viljem Vek $^{2} \cdot$ Ida Poljanšek $^{2} \cdot$ Virpi Virjamo $^{1,3} \cdot$ Yeray Manuel López-Gómez ${ }^{1}$. \\ Tuomo Sainio $^{4} \cdot$ Miha Humar $^{2}$. Primož Oven ${ }^{2} \cdot$ Antti Haapala $^{1}$
}

Received: 17 September 2021 / Accepted: 25 December 2021 / Published online: 9 January 2022

(c) The Author(s) 2022

\begin{abstract}
Purpose Norway spruce log soaking water (SLSW) is considered a waste in the plywood and veneer industry but has not been characterised, and its possible uses remain unexplored. The purpose of this study is to characterise and test the possibility of using SLSW in wood preservative formulations.

Methods First, the SLSW was characterised, and the presence of carbohydrates in the log soaking water was reduced with a hydrophobic adsorbent to reduce the nutrient availability for fungi in the liquids. Then, the feasibility of using SLSW and the sugar free SLSW (denoted later as EHC solution) as wood preservatives was studied by testing their antifungal and antioxidant activities and performing a mini-block test against Schizophyllum commune, Trametes versicolor, Fibroporia vaillantii and Gloeophyllum trabeum.

Results Several phenolic compounds were found in the SLSW. This water also had high antioxidant activity at $1000 \mathrm{mg} / \mathrm{L}$ before and after carbohydrate removal but no antifungal activity. Its impregnation in wood caused a slight reduction in mass loss of the Pinus sylvestris specimens but had no effect on the Fagus sylvatica specimens when exposed against Schizophyllum commune, Trametes versicolor, Fibroporia vaillantii and Gloeophyllum trabeum.

Conclusion The SLSW as a wood preservative is invalid, even after partial carbohydrate removal. However, due to the presence of wood constituents, SLSW could be a resource for other uses requiring high antioxidant activity but specific applications need further investigation.
\end{abstract}

\section{Graphical Abstract}

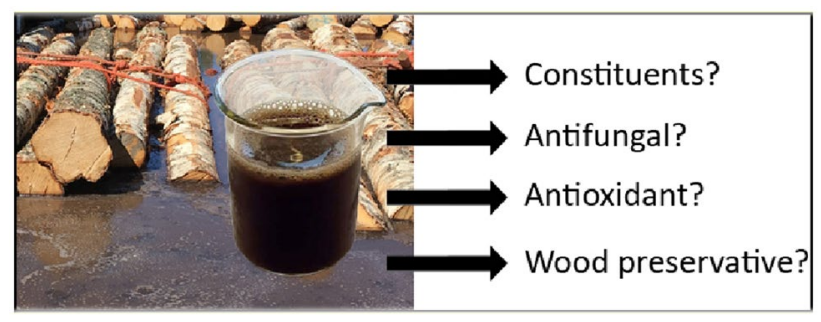

Keywords Log soaking liquid · Wood degradation · Natural chemicals · Biorefining · Pinus sylvestis $\cdot$ Fagus sylvatica

Aitor Barbero-López

Aitor.barberolopez@uef.fi

Extended author information available on the last page of the article

\section{Statement of Novelty}

Log soaking water from Norway spruce is discarded as waste in the plywood industry. Concurrently, the wood industry is searching for new-generation wood preservatives due to the high toxicity to humans and the environment of the currently 
used ones. Unprecedentedly, this study characterised SLSW and tested the possibility of using this waste as a potential wood preservative. Furthermore, the constituents found in SLSW also highlight the possibility of using this waste as a possible source of chemicals in other industries.

\section{Introduction}

Log soaking is a standard pre-treatment in the plywood, laminated veneer lumber and veneer industries that facilitates the later debarking of the logs treated. For the bark and the wood beneath to soften, the logs are submerged in warm water for several hours or days, with the temperature varying depending on the wood species and properties [1]. Many factors affect the temperatures used in this process. Nordic countries, such as Finland, use water between 20 and $70^{\circ} \mathrm{C}$, but outdoor conditions [1] and the specific practices performed by each company [2] will cause variations in these temperatures. Some wood and bark constituents, such as saccharides and several extractives [3] including phenolic compounds [4], leach into the water [5]. Considering that water is replaced very gradually or only a few times each year, the concentration of chemicals in water might be high. However, the chemical constitution of this water from several species, such as Norway spruce (Picea abies), remains unexplored, and it is discarded as waste.

Enhancing wood durability is a major goal of the wood and construction industry, as wood with insufficient durability in most applications would require substitution often and would not be feasible for many end-uses, such as outdoor constructions, bridges, decking and cladding. Wood preservatives are used to prevent decay and prolong the service life of wood in exposed applications. However many of the traditional preservatives were removed from the service, such as chromated copper arsenate (CCA) and pentachlorophenol 30 years ago in European Union [6]. Other wood preservatives are harmful to humans, such as creosotes, which are considered carcinogenic [7], but there are few adequate substitutes in the market, so their uses remain permitted [8]. Additionally, society's increasing concern about toxic chemicals and the lack of knowledge about the synergetic effects of many chemicals may drive stricter regulations on chemicals and sustainability. Thus, new alternative wood preservatives are needed, which have less undesirable effects on the environment and still perform appropriately in wood.

Wood, bark and plant extractives have often been suggested as possible alternative preservatives. Extractives have been considered responsible for wood's durability for many decades [9]. Within all the extractives, phenolics play a relevant role in wood decay resistance [10]. Some phenolics, such as tannins, have been successfully tested as antifungals and wood-decay fungi inhibitors [11, 12]. European beech (Fagus sylvatica L.) wound-wood methanol extracts [13] and several Eucalyptus spp. leaf extracts [14] have also been found effective against decay fungi. Other bio-based chemicals, such as wood pyrolysis distillates [15] and essential oils [16], have also been found to inhibit wood-decay fungi, likely due to organic acids and phenols. According to EU Biocidal products regulation, one of the limitations preventing the broader utilisation of these compounds is the complex-expensive and time-demanding authorisations required.

The extractives or bio-based chemicals used for wood preservative formulations should be obtained from industrial side streams and residues to keep the price low and promote the utilisation of materials. Many side-streams and wastes contain chemical compounds with antifungal properties, such as pyrolysis distillates from Scots pine (Pinus sylvestris L.) wood chips [17] and coconut shell [18], Scots pine knotwood extracts [19], and coffee silverskin extracts [20]. The antifungal or wood-preserving properties of these bio-based mixtures are often related to the lignin-rich fractions [21] of pyrolysis distillates and the presence of organic acids such as acetic, formic and propionic acids [22]. Some neolignans, such as magnolol and honokiol [23, 24], and stilbenes [25], have been proven to be antifungal. Gallic acid, commonly found in plant extracts, and vanillic acid have been identified as antifungal phenolics [26, 27]. The previously cited log soaking water contain many chemicals from wood and bark of interest for wood preservative formulations.

In this study, we characterised and tested the possibility of using Norway spruce log soaking water (SLSW) and a solution obtained by enriching hydrophobic compounds recovered from SLSW as wood preservatives. SLSW has only been tested as a wood preservative once with no promising results, but this study focused in a broad spectrum of different wood preservatives and did not study the composition of log soaking water in any detail [28]. We expected that soaking water contained Norway spruce bark-derived phenolics, but other possible compounds, such as free carbohydrate monomers, that may promote microbial growth.

\section{Materials and Methods}

Norway spruce (P. abies) log soaking water (SLSW) for this experiment was obtained from a Norway spruce plywood mill site located in southern Finland. The SLSWs were stored at $5{ }^{\circ} \mathrm{C}$ until used for the tests to minimize additional fungal or bacterial contamination.

\section{Characterisation of SLSW}

High-performance liquid chromatography (HPLC) analysis for phenolic composition [20] was performed to analyse the 
crude SLSW before any other test. Filtered (Syringe Filter with cellulose membrane of pore size $0.45 \mu \mathrm{m}$, Agilent Technologies) samples were analysed by HP 1100 series LC-system (Agilent Technologies, Palo Alto, CA) equipped with a diode array detector (DAD), where the reverse-phase separation was performed on a Hypersil ODS $75 \mathrm{~mm} \times 4.6 \mathrm{~mm}$ i.d. RP C18 column. Phenols were separated by gradient elution using aqueous $1.5 \%$ tetrahydrofuran $+0.25 \%$ orthophosphoric acid (A) and methanol as eluents. The following elution gradient was used: $0-5 \min 100 \%$ A, 5-10 $\min 85 \%$ A, $10-20 \min 70 \% \mathrm{~A}$ and $20-50 \mathrm{~min} 50 \% \mathrm{~A}$. The flow rate was $2 \mathrm{~mL} / \mathrm{min}$, the column temperature was $30^{\circ} \mathrm{C}$, and the injection volume was $20 \mu \mathrm{L}$. The compounds were detected at 220,270 and $320 \mathrm{~nm}$. The tentative identification was based on similarities in spectral characteristic found in the literature and the retention time and UV spectrum of commercial standards.

The quantification $(\mathrm{mg} / \mathrm{L})$ of compounds in SLSW was based on commercial standards as follows: $(+)$-catechin (PhytoLab GmbH \& Co. KG, Germany) for (+)-catechin,, dihydromyricetin (ampelopsin) (Extrasynthese, France) for ampelopsin and taxifolin (detected from $320 \mathrm{~nm}$ ), piceatannol (Sigma, USA) for stilbenes (detected from $270 \mathrm{~nm}$ ), gallic acid (Aldrich, Germany) for gallic acid (detected from $220 \mathrm{~nm}$ ), cinnamic acid (Sigma, USA) for cinnamic acid derivates (detected from $220 \mathrm{~nm}$ ), protocatechuic acid (Sigma, USA) for protocatechuic acid derivative (detected from $220 \mathrm{~nm}$ ), vanillic acid (Fluka AG, Switzerland) for vanillic acid (detected from $220 \mathrm{~nm}$ ) and procyanidin B2 (Phytolab GmbH \& Co.KG., Germany) for procyanidins (detected from $220 \mathrm{~nm}$ ). Concentration of lignans and neolignans (detected from $220 \mathrm{~nm}$ ) are estimated as (+)-catechin equivalents. All HPLC results are the averages of two parallel samples. After the HPLC run, condensed tannins (proanthocyanidins) were used with an acid-butanol assay, according to Hagerman [29]. Norway spruce bark condensed tannins were used as a reference.

In the preliminary characterisation of the crude SLSW, the presence of the following three sugars were tested: sucrose, D-fructose and D-glucose were analysed from filtered (Whatman 42 ashless) liquid samples with a K-SUFRG enzymatic assay kit (Megazyme, Ireland) following the manufacturer's protocol. Samples were analysed as duplicates, and additional colour blanks were used as controls for the coloured samples.

\section{Preparation of the Solution with Enriched Hydrophobic Compounds (EHC) from SLSW by Adsorption}

Adsorption on XAD-16N hydrophobic adsorbent (Sigma, USA) was used to recover and purify hydrophobic compounds in SLSW. Monomeric free carbohydrates were the main impurities removed. The adsorption experiments were done at $50{ }^{\circ} \mathrm{C}$ using a packed bed (glass column, length $70.0 \mathrm{~cm}$ and diameter $1.5 \mathrm{~cm}$ ). The flow rate was $4.0 \mathrm{BV} / \mathrm{h}$ (bed volumes per hour, equivalent to $8.2 \mathrm{~mL} / \mathrm{min}$ ). The adsorbent was loaded with SLSW for $11 \mathrm{BV}$ and washed with deionised water for $1.2 \mathrm{BV}$ to remove carbohydrates. Removal was confirmed by HPLC analyses (Agilent 1100, Agilent Technologies, Inc. Detector: RI; column: Agilent Metacarb $87 \mathrm{H}$ at $T=65^{\circ} \mathrm{C}$; injection volume: $10 \mu \mathrm{L}$; eluent: $5 \mathrm{mmol} / \mathrm{L}$ sulfuric acid at $0.6-0.8 \mathrm{~mL} / \mathrm{min}$ ) at 105 the free carbohydrates eluted in the washing step. Nearly identical methods have been previously used, for example, by Eisenhuber et al. [30]. The compounds adsorbed on XAD-16N were desorbed with 99.8 wt\% ethanol (AnalaR Normapur, VWR) for 2.0 BV. Before the next cycle, ethanol was displaced from the column with 3.0 BV of deionised water. Up to 13 adsorption-washing-desorption-washing cycles were run, and the desorbed solutions were combined with identical solutions in all application tests.

Ethanol used as a desorbent in the recovery and purification of hydrophobic compounds from SLSW was substituted with MilliQ water (Merck KGaA, Darmstadt, Germany). This step was done by condensing the solution enriched with hydrophobic compounds (EHC) in a Rotavapor ${ }^{\circledR}$ R-300 (Büchi AG, Flawil, Switzerland), reaching the ethanol boiling point and adding MilliQ water when the EHC were condensed. The process was repeated three times to ensure that no ethanol remained in the purified EHC.

\section{Sample Preparation and Characterisation of SLSW and EHC for Bioactivity Experiments}

To perform further tests, the crude SLSW and EHC were condensed in a rotavapor at temperatures $\leq 50^{\circ} \mathrm{C}$ and freezedried overnight in a Telstar LyoQuest CC1930 at $-85{ }^{\circ} \mathrm{C}$ and 0.045 mbar. The same process was done for the commercial reference Silvanolin (Silvaprodukt, Ljubljana, Slovenia). This is a commercial wood preservative comprising copper, ethanolamine, quaternary ammonium compound and boron [31].

The total amount of dry solids in crude SLSW and EHC were determined gravimetrically by drying the volume aliquots of each extract to the constant mass at $105^{\circ} \mathrm{C}(\mathrm{mg} / \mathrm{L})$. According to Hayes, sugar contents from dried water extraction materials were dissolved with water, and sugar contents were determined [32]. The presence of sugars in these liquids was studied as they may act as a source of nutrients for several microbes. After incubation, the secondary hydrolysis was done by diluting solutions to $4 \% \mathrm{H}_{2} \mathrm{SO}_{4}$ and autoclaved at $121{ }^{\circ} \mathrm{C}$ for $60 \mathrm{~min}$. Standard samples with $10 \mathrm{~mL}$ of a known sugar solution and $348 \mu \mathrm{L}$ of $72 \%$ $\mathrm{H}_{2} \mathrm{SO}_{4}$ were prepared and autoclaved to determine sugar loss 
during autoclaving. The autoclaved samples and standard mixtures were filtered and analysed according to their sugar compositions.

Before being exposed to fungi, total phenols and proanthocyanidins were semi-quantitatively checked in the SLSW and EHC samples, according to Vek et al. [19], which is essentially a modified protocol from those described by Broadhurst and Jones [33], Singleton and Rossi [34] and Scalbert et al. [35]. Briefly, the first 1\% (w/v) SLSW and EHC samples were diluted so that the measured absorbances fit the concentration range of the spectrophotometric methods. Colorimetrical analysis was conducted on a Perkin-Elmer Lambda UV-Vis spectrophotometer (Waltham, MA, USA). Total phenols in the solutions were measured at $765 \mathrm{~nm}, 120 \mathrm{~min}$ after diluted Folin-Ciocalteu phenol reagent (aq) and an aqueous sodium carbonate solutions were added to the samples. The content of proanthocyanidins was measured using a vanillin- $\mathrm{HCl}$ assay by adding $4 \%$ vanillin solution (w/v methanol) and concentrated $\mathrm{HCl}$ to the samples. After the reaction mixture was kept at RT for $20 \mathrm{~min}$, the absorbances were measured at $500 \mathrm{~nm}$. Gallic acid and catechin were used as references for semi-quantitative analyses of total phenols and proanthocyanins, respectively. Both spectroscopic methods were linear in the selected concentration range $\left(R^{2} \geq 0.99\right)$. The results were expressed as $\mathrm{mg} / \mathrm{L}$ of gallic acid and catechin equivalents, respectively.

\section{Antioxidant Test}

The 2,2-diphenyl-1-picrylhydrazyl (DPPH) radical-scavenging activity of the SLSW and EHC samples was analysed following the protocol described by Vek et al. [19]. Briefly, $0.1 \%$ (w/v) solutions of SLSW and EHC and the aqueous solutions of the references (gallic acid, GA; ascorbic acid, AA; butyl hydroxyanisole, BHA) were tested for antioxidant activity in five testing concentrations (from 1000 to $50 \mathrm{mg} / \mathrm{L}$ ). Water alone was used as a control. A DPPH methanol solution $(40 \mathrm{mg} / \mathrm{L})$ was mixed with the SLSW, EHC samples and reference antioxidants. After $30 \mathrm{~min}$ of incubation at RT, the reduction of the DPPH radical was measured by taking the absorbance at $517 \mathrm{~nm}$. The results were expressed as DPPH free radical-scavenging activity (RSA, \%) [36, 37].

\section{Antifungal Test}

The fungal species chosen for this experiment were the brown rot fungi Fibroporia vaillantii (ZIM L037) and Gloeophyllum trabeum (ZIM L018), and the white rot fungi Schizophyllum commune (ZIM L039) and Trametes versicolor (ZIM L039). These fungi were chosen as they are species which are often appearing on wood in use class 2 to use class 4 applications in Central Europe [38]. The fungi originated from the culture collection of industrial microorganisms [39] the Biotechnical Faculty, University of Ljubljana, and are available on demand.

The crude SLSW and purified EHC were then diluted in dimethyl sulfoxide (DMSO) at concentrations (w:v) of 5 and $1 \%$ as solvent for natural product bioassays [38] that has no interaction with fungi [40]. Silvanolin was diluted in DMSO at 5,1 and $0.5 \%$ concentrations (w:v). To test the partial substitution of Silvanolin with SLSW, two dilutions were prepared containing $4.5 \%$ pure SLSW and $0.5 \%$ silvanolin in the first dilution and $0.5 \%$ pure SLSW and $0.5 \%$ silvanolin in the second dilution, resulting in mixtures with a total concentration (w:v) of 5 and $1 \%$, respectively.

Petri dishes $(\varnothing 90 \mathrm{~mm})$ were prepared with about $20 \mathrm{~mL}$ of growth media containing $3.9 \%$ potato dextrose agar in distilled water. A borer ( $77 \mathrm{~mm}$ ) was used to make three bores that had the centre $10 \mathrm{~mm}$ far from the edge of each Petri dish containing 3.9\% potato dextrose agar and kept at $120^{\circ}$ angle between each bore. In each Petri dish, one of the solutions -crude SLSW, EHC or the EHC and silvanolin mixture - was added, by pipetting $0.1 \mathrm{~mL}$ of the $5 \%$ solution in one of the bores, $0.1 \mathrm{~mL}$ of the $1 \%$ solution in the second bore and $0.1 \mathrm{~mL}$ of DMSO in the third bore, to be used as control. For silvanolin, four bores were made following the same process in the Petri dish, leaving $90^{\circ}$ between the bores, and the holes filled with either 5, 1 or $0.5 \%$ silvanolin and pure DMSO. The Petri dishes were sealed with plastic film and left overnight to allow the extracts to disperse around the bore.

Under sterile conditions, the fungi were then inoculated in the petri dish. One fungal species was put in the centre of each Petri dish using a borer $(\varnothing 7 \mathrm{~mm})$. Nine replicates were prepared for each fungal species and treatmentcrude SLSW, EHC solution, silvanolin and the EHC solution mixture. The Petri dishes were incubated at $25^{\circ} \mathrm{C}$ and $75 \% \mathrm{RH}$ and fungal growth was followed daily, beginning four days after inoculation, and the experiment was terminated when the fungus reached the edge of the petri dish. The inhibition caused by each chemical concentration was determined by measuring the growth percentage of the fungus towards the bore centre containing the chemical and compared to the growth towards the control bore centre in the same petri dish with the following formula:

Inhibition $(\%)=1-($ Growth towards the chemical

$$
\text { /Control growth) } \cdot 100
$$

The mean value of all the inhibitions for each fungus and chemical concentration $(\mathrm{N}=9)$ was then calculated. The statistical analysis of the antifungal activity was performed using IBM SPSS Statistics 27, using Tukey's range test as post-hoc for ANOVA. 


\section{Mini-Block Test}

The performance of crude SLSW and EHC in treating wood against decay was tested following a mini-block procedure and a modified version of EN 113, where flasks were substituted with Petri dishes.

Petri dishes containing $3.9 \%$ potato dextrose agar (prepared following the same steps as in the antifungal test) were inoculated with the wood-decaying fungi Fibroporia vaillantii, Gloeophyllum trabeum, Schizophyllum commune or Trametes versicolor. The petri dishes were incubated at $25^{\circ} \mathrm{C}$ and $75 \% \mathrm{RH}$ until the mycelia reached the edge of the petri dish.

European beech (Fagus sylvatica) wood and Scots pine (Pinus sylvestris) sapwood specimens of $40 \times 10 \times 5 \mathrm{~mm}^{3}$ were oven dried at $60^{\circ} \mathrm{C}$ and weighed before being impregnated with $1 \%$ dilutions in the distilled water of crude SLSW, EHC, with only distilled water to be used as a control. The impregnation was performed by submerging the wood specimens in dilutions and distilled water and at a vacuum $(25 \mathrm{kPa})$ for $30 \mathrm{~min}$, and afterwards a pressure of 900 to $1000 \mathrm{kPa}$ for $1 \mathrm{~h}$. The specimens were weighed to determine solution uptake before being oven dried at $60^{\circ} \mathrm{C}$. The dry mass at $60{ }^{\circ} \mathrm{C}$ before and after impregnation was recorded to quantify the amount of chemicals retained by the wood. Then, the wood specimens were sterilised at $120^{\circ} \mathrm{C}$ for $15 \mathrm{~min}$ ) and under sterile conditions, they were put in the grown colonies of the previously cultivated fungi, separating the wood from the agar by putting the specimens over an inert plastic mesh which was put over the agar. Three specimens were put in each petri dish, one each treated with $1 \%$ crude SLSW, $1 \%$ EHC solution or distilled water to be used as a control specimen. The petri dishes were sealed using plastic film and incubated at $25{ }^{\circ} \mathrm{C}$ and $75 \% \mathrm{RH}$ for 16 weeks. A total of 7 replicates of each treatment and wood species were exposed to each wood-decaying fungus. After this time, the wood specimens were collected, and the mycelium was gently removed using a brush. The wood specimens were oven dried at $60{ }^{\circ} \mathrm{C}$ until a constant mass was reached, and the mass was recorded. The mass loss compared to the impregnated wood before decay was calculated.

\section{Mechanical Test of Treated Wood}

European beech (Fagus sylvatica) wood and Scots pine (Pinus sylvestris) sapwood specimens of $40 \times 10 \times 5 \mathrm{~mm}^{3}$ were impregnated with either $1 \%$ dilutions in distilled water of crude SLSW or $1 \%$ EHC solution, or with only distilled water to be used as controls. The impregnation was performed by submerging the wood specimens in dilutions and distilled water and keeping the submerged at a vacuum of $25 \mathrm{kPa}$ for $30 \mathrm{~min}$, and afterwards a pressure of 900 to $1000 \mathrm{kPa}$ for $1 \mathrm{~h}$. The specimens were oven dried at $60{ }^{\circ} \mathrm{C}$ until a constant mass was reached. For each treatment and wood species, six replicates were prepared. The wood specimens were conditioned to constant weight at $20{ }^{\circ} \mathrm{C}$ and $65 \%$ RH.

The mechanical testing of the wood specimens was performed using a Zwick Roell 050 materials testing setup and modulus of elasticity ( $\mathrm{E}_{\mathrm{mod}}$ ), and modulus of rupture (MOR) were calculated by performing a three point bending test. The mean values of the $\mathrm{E}_{\text {mod }}$ and MOR for the different treatments in Scots pine sapwood and European beech were calculated to understand how the wood impregnation with these liquids would affect the mechanical properties of wood.

\section{Statistical Analyses}

The statistical analysis of the antifungal activity, wood decay and mechanical tests were performed using IBM SPSS Statistics 27 and Tukey's range test as post-hoc for ANOVA at a significance level of $95 \%$.

\section{Results}

\section{Preliminary Characterisation of Crude SLSW}

The total dissolved solids in the SLSW was $1.3 \%$. The concentrations of sucrose, D-fructose and D-glucose in crude SLSW were too low to be quantified.

Table 1 shows the individual phenolic compounds identified in the HPLC analysis of the crude SLSW. Proanthocyanidins $(0.37 \mathrm{~g} / \mathrm{L})$ and lignans were present in the crude SLSW at the highest concentration, and different flavonoids and procyanidins were also found. Stilbenes and phenolic acids occurred at low concentrations in the crude SLSW.

\section{Comparison of Chemical Characteristics of Crude SLSW and EHC Solutions}

The total carbohydrate content in the crude SLSW exceeded that of the EHC solution (Table 2). The amounts of oligomeric and free carbohydrates were reduced by the adsorptive recovery and purification method, although some were retained. The amount of free carbohydrates in particular was reduced by $79 \%$ to below $0.1 \mathrm{wt} \%$ of dry matter.

The diluted EHC samples contained larger amounts of total phenols (TP) (313.36 (SD 36.76) $\mathrm{mg} / \mathrm{L})$ and proanthocyanidins (PAC) (32.86 (SD 3.65) $\mathrm{mg} / \mathrm{L})$ than the SLSW samples (total phenols $=105.32(\mathrm{SD} 7.97) \mathrm{mg} / \mathrm{L}$; proanthocyanidins $=10.04(\mathrm{SD} 3.63) \mathrm{mg} / \mathrm{L})$. EHC extract comprised $0.70 \mathrm{TP}$ and $0.07 \mathrm{PAC}$, and shares of TP and PAC in the SLSW extract were calculated to be 0.58 and 0.10 , respectively. Hence, the presence of phenolic compounds 
Table 1 Concentrations of identified phenolic compounds in crude SLSW sample. Concentration of lignans are reported as (+)-catechin equivalents. Glu. refers to glucoside and der. to derivative

\begin{tabular}{lclc}
\hline Compounds & $\begin{array}{c}\text { Concen- } \\
\text { tration } \\
(\mathrm{mg} / \mathrm{L})\end{array}$ & Compounds & $\begin{array}{c}\text { Concentra- } \\
\text { tion (mg/L) }\end{array}$ \\
\hline Flavonoids & & Neolignan der. 3 & 109.95 \\
Ampelopsin & 1.57 & Neolignan der. 4 & 2.04 \\
Taxifolin & 8.77 & Neolignan der. 5 & 1.18 \\
(+)-catechin & 29.39 & Phenolic acids & \\
Lignans & & Cinnamic acid der. 1 & 1.97 \\
Lignan der. 1 & 7.85 & Cinnamic acid der. 2 & 3.01 \\
Lignan der. 2 & 2.84 & Gallic acid & 0.66 \\
Lignan der. 3 & 8.62 & Protocatechuic acid der & 2.07 \\
Lignan der. 4 & 7.32 & Vanillic acid & 2.86 \\
Lignan der. 5 & 2.71 & Procyanidins & \\
Lignan der. 6 & 7.07 & Procyanidin 1 & 9.99 \\
Lignan der. 7 & 6.82 & Procyanidin 2 & 3.10 \\
Lignan der. 8 & 11.49 & Procyanidin 3 & 4.07 \\
Lignan der. 9 & 1.84 & Procyanidin 4 & 17.38 \\
Lignan der. 10 & 2.25 & Stilbenes & \\
Lignan der. 11 & 3.54 & Piceatannol der & 8.53 \\
Neolignan der. 1 & 2.36 & Piceatannol glu & 4.05 \\
Neolignan der. 2 & 71.83 & Resveratrol & 7.96 \\
\hline & & &
\end{tabular}

Table 2 Total carbohydrate, free carbohydrate and oligomeric carbohydrate content (as the \% of dry matter) in crude Norway spruce log soaking water (SLSW) and solution with enriched hydrophobic compounds (EHC solution) values represent $\%$ dry matter weight, while values in parentheses represent standard error

\begin{tabular}{llll}
\hline & $\begin{array}{l}\text { Total carbohy- } \\
\text { drate content }\end{array}$ & Free carbohydrates & $\begin{array}{l}\text { Oligomeric } \\
\text { carbohy- } \\
\text { drates }\end{array}$ \\
\hline Crude SLSW & $11.61(0.04)$ & $0.43(0.00)$ & $11.18(0.04)$ \\
EHC solution & $9.99(0.03)$ & $0.09(0.00)$ & $9.90(0.03)$ \\
\hline
\end{tabular}

and condensed tannins in the SLSW were confirmed before the solutions were used for further fungal tests.

\section{Antioxidant Test}

The results of the DPPH radical-scavenging activity - the antioxidant activity - of the crude SLSW or EHC solution were similar to the references (butylated hydroxyanisole, ascorbic acid and gallic acid) at concentrations at and above $500 \mathrm{mg} / \mathrm{L}$ but markedly lower at lower concentrations (Table 3). The EHC solution had higher antioxidant activity than the crude SLSW, with a value like the references at a concentration of $500 \mathrm{mg} / \mathrm{L}$. However, the EHC solution at concentrations lower than $500 \mathrm{mg} / \mathrm{L}$ did not perform as in the references.

\section{Antifungal Test}

None of the tested concentrations of crude SLSW and EHC solution significantly inhibited the wood-decaying fungi tested (Table 4). Additionally, 5\% concentration of both crude SLSW and EHC solution performed worse against the fungi than a $1 \%$ concentration in most cases. The addition of Silvanolin to crude SLSW and EHC solution at different concentrations improved their performance and significant inhibition was achieved in several fungi species in some of the mixtures. Similar levels of inhibition as caused by Silvanolin alone at the same concentration as used in the mixture $(0.5 \%)$ was not achieved.

As found in the crude SLSW and EHC solutions, the lower concentration of these chemicals resulted in higher efficiency against the fungi of the SLSW and silvanolin mixtures. The commercial reference silvanolin outperformed the wood-decaying fungi, even at the lowest concentration, and inhibited almost $50 \%$ G. trabeum at the highest concentration, while $S$. commune and $T$. versicolor were inhibited over $70 \%$ at similar concentration. Finaly, $F$. vaillantii did not grow in the Petri dishes where silvanolin was tested, not even towards the bores where the control solution was tested, as silvanolin presence in the malt agar media probably inhibited the fungus. This follows previous observations. Silvanolin was designed to inhibit the growth of white and brown rot fungi [41].
Table 3 Antioxidant activity of the Norway spruce log soaking water (SLSW), solution with enriched hydrophobic compounds (EHC solution) and the references, butylated hydroxyanisole, ascorbic acid and gallic acid

\begin{tabular}{llllll}
\hline $\begin{array}{l}\text { Concentration } \\
(\mathrm{mg} / \mathrm{L})\end{array}$ & $\begin{array}{l}\text { Crude SLSW } \\
(\%)\end{array}$ & $\begin{array}{l}\text { EHC solution } \\
(\%)\end{array}$ & $\begin{array}{l}\text { Butylated hydroxy- } \\
\text { anisole }(\%)\end{array}$ & $\begin{array}{l}\text { Ascorbic acid } \\
(\%)\end{array}$ & Gallic acid (\%) \\
\hline 1000 & 77.5 & 80.9 & 84.5 & 88.6 & 86.7 \\
500 & 50.0 & 81.7 & 83.6 & 88.8 & 85.8 \\
250 & 32.3 & 54.3 & 71.2 & 88.3 & 85.5 \\
100 & 14.4 & 22.3 & 46.8 & 55.3 & 85.6 \\
50 & 9.6 & 14.8 & 23.2 & 27.0 & 70.5 \\
\hline
\end{tabular}


Table 4 Inhibition caused by Norway spruce log soaking water (SLSW), solution with enriched hydrophobic compounds (EHC solution), silvanolin and the mixtures between pure and crude SLSW and silvanolin against Schizophyllum commune, Trametes versicolor, Fibroporia vaillantii and Gloeophyllum trabeum

\begin{tabular}{lcccc}
\hline \multicolumn{5}{c}{ Inhibition $\%$ (mean \pm SE) } \\
\cline { 2 - 5 } & S. commune & G. trabeum & T. versicolor & F. vaillantii \\
\hline Crude SLSW 1\% & $12.1 \pm 1.6$ & $3.1 \pm 2.0$ & $8.5 \pm 4.7$ & $-0.1 \pm 5.0$ \\
Crude SLSW 5\% & $6.5 \pm 1.6$ & $-7.9 \pm 3.2$ & $-8.2 \pm 3.5$ & $-7.4 \pm 5.6$ \\
EHC solution 1\% & $8.7 \pm 3.3$ & $4.9 \pm 2.9$ & $-5.5 \pm 6.2$ & $0.3 \pm 5.5$ \\
EHC solution 5\% & $7.4 \pm 4.4$ & $-6.0 \pm 5.2$ & $-17.5 \pm 4.8$ & $5.5 \pm 1.8$ \\
Crude SLSW + Silvanolin 1\% & $20.5 \pm 1.8^{*}$ & $23.6 \pm 3.1^{*}$ & $9.1 \pm 2.2$ & $7.8 \pm 4.6$ \\
Crude SLSW + Silvanolin 5\% & $10.4 \pm 1.4$ & $1.8 \pm 3.8$ & $-13.1 \pm 8.3$ & $-12.7 \pm 1.9$ \\
EHC solution + Silvanolin 1\% & $7.8 \pm 3.8$ & $20.0 \pm 1.4^{*}$ & $6.9 \pm 4.4$ & $23.1 \pm 2.7^{*}$ \\
EHC solution + Silvanolin 5\% & $15.7 \pm 1.5^{*}$ & $7.8 \pm 1.6$ & $-15.2 \pm 7.3$ & $0.8 \pm 4.8$ \\
Silvanolin 0.5\% & $38.3 \pm 1.3^{*}$ & $24.9 \pm 3.4^{*}$ & $33.1 \pm 5.3 *$ & $100+0^{*}$ \\
Silvanolin 1\% & $55.6 \pm 4.7^{*}$ & $33.3 \pm 2.6^{*}$ & $48.8 \pm 6.8^{*}$ & $100 \pm 0^{*}$ \\
Silvanolin 5\% & $75.2 \pm 3.5^{*}$ & $47.3 \pm 1.4^{*}$ & $72.7 \pm 2.4^{*}$ & $100 \pm 0^{*}$ \\
Control (DMSO) & $0.0 \pm 0.0$ & $0.0 \pm 0.0$ & $0.0 \pm 0.0$ & $0.0 \pm 0.0$ \\
\hline
\end{tabular}

The results are presented as the mean inhibition of all replicates (mean value \pm standard error). Negative values indicate growth enhancement caused by the tested liquid or mixture. To facilitate the reading, only the results that significantly differed from controls (bores with only DMSO) of the same fungal species according to Tukey's test performed as a post-hoc for the ANOVA test were marked with an asterisk

\section{Mini-Block Test}

The mass loss of the reference specimens exposed to the decay fungi, except for S. commune, was sufficiently high to consider the strain as virulent (Fig. 1A). This proves that the wood was susceptible and that fungal cultures were vital. As expected, brown rot fungi were more effective in decaying Scots pinewood, while for hardwoods, white rot fungi were more effective [42]. The overall results of the mini-block test showed a small improvement in the mass loss of $1 \%$ crude SLSW and EHC solution-treated Scots pine sapwood compared to wood specimens treated with only distilled water when exposed to T. versicolor and G. trabeum. In most cases the differences were not meaningful to consider chemicals as effective. The fungus $S$. commune did not cause an important mass loss in any Scots pine specimens, and F. vailantii caused the highest mass loss in the Scots pine sapwood specimens treated with $1 \%$ EHC solution, which differed significantly from the other groups. The treated European beech wood specimens did not show any improvement in their performance when compared with the distilled watertreated wood specimens (Fig. 1B).

Like in Scots pine sapwood, T. versicolor and G. trabeum caused the highest mass loss also in European beech. Both fungal species are known as effective wood degrading organisms, that can effectively decay non durable beech wood. These two fungi can be frequently observed on softwood and hardwood in outdoor applications [42]. Regarding $S$.
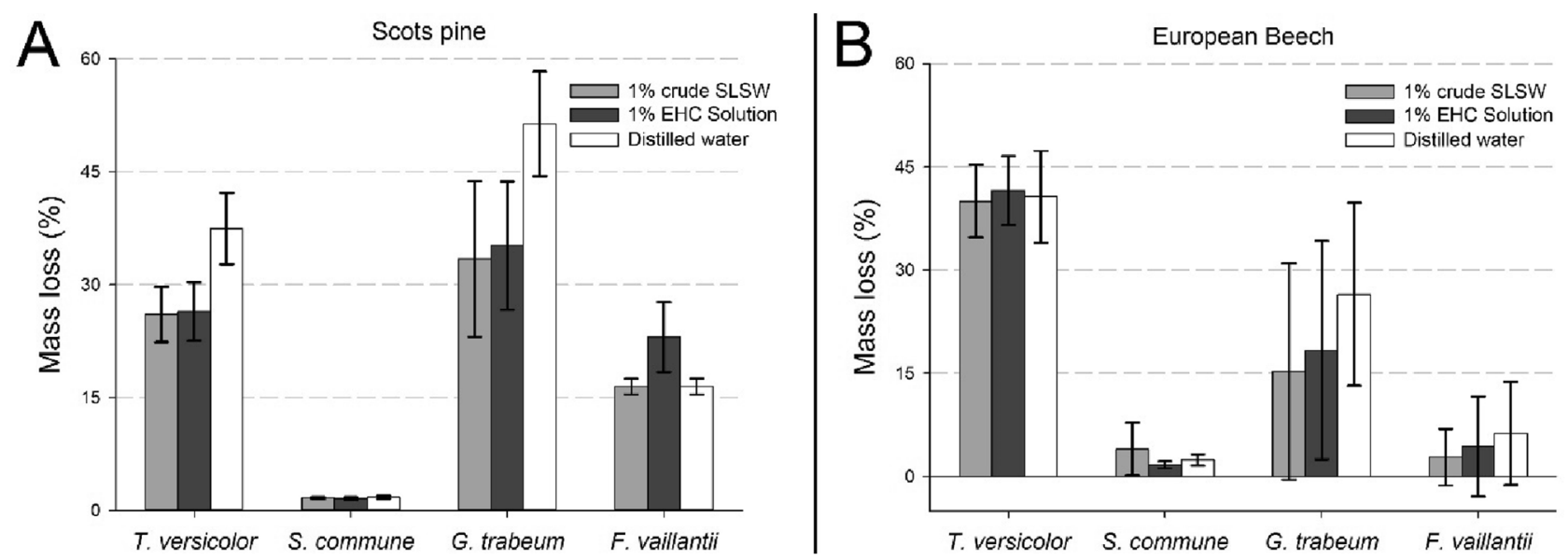

Fig. 1 Mass loss (\%) of Scots pine sapwood specimens (A) and European beech wood specimens (B) after 16 weeks of exposure to the decay fungi Trametes versicolor, Schizophyllum commune, Gloeophyllum trabeum and Fibroporia vaillantii 
commune and $F$. vaillantii, they caused almost no mass loss to the European beech wood regardless of the treatment. Fibroporia vaillanti is predominately found on softwoods, while $S$. commune, as primary colonizer, could decay wood in harsh environment. Both fungi were used, as they do exhibit high tolerance to some of the commercial biocides and secondary metabolites. Even more, sometimes presence of biologicaly active ingredients even stimulates fungal growth [41]. In overall, the presence of SLSW and EHC solution in European beech wood did not cause relevant inhibition of the wood-decaying fungi.

\section{Mechanical Test}

The results of $\mathrm{E}_{\text {mod }}$ showed significant differences between different wood treatments applied to Scots pine sapwood (Table 5) but showed no significant differences in MOR. Concerning the European beech specimens, the EHC solution caused a small — but statistically significant-improvement in $\mathrm{E}_{\text {mod }}$ and MOR of European beech specimens. In both wood species, the $\mathrm{E}_{\text {mod }}$ was significantly higher for wood treated with the EHC solution.

\section{Discussion}

The crude SLSW contained phenolic acids, lignans, flavonoids, stilbenes and procyanidins eluted from the woods soaked on them. These constituents identified in crude SLSW are commonly present in Norway spruce bark [43]. The concentrations of proanthocyanidins and phenolics exceeded those found in other extracts previously tested as possible wood preservatives, such as coffee silverskin [20]. The adsorptive recovery and purification method reduced the carbohydrate content while increasing the proanthocyanidin concentration in the resulting EHC solution.

Carbohydrates were identified in the crude SLSW and the EHC solutions, but their concentrations were $79 \%$ lower in

Table 5 Modulus of elasticity $\left(\mathrm{E}_{\mathrm{mod}}\right)$ and modulus of rupture (MOR) of Scots pine and European beech wood specimens treated with distilled water (Control), Norway spruce log soaking water (SLSW) and solution with enriched hydrophobic compounds (EHC solution)

\begin{tabular}{lcc}
\hline & $\mathrm{E}_{\text {mod }}(\mathrm{GPa})$ & $\mathrm{MOR}(\mathrm{MPa})$ \\
\hline Scots pine & & \\
Distilled water & $5.6 \pm 0.3^{\mathrm{a}}$ & $108.9 \pm 7.8$ \\
Crude SLSW & $6.1 \pm 0.3^{\mathrm{ab}}$ & $119.0 \pm 6.2$ \\
EHC solution & $6.4 \pm 0.3^{\mathrm{b}}$ & $114.0 \pm 4.9$ \\
European beech & & \\
Distilled water & $5.9 \pm 0.1^{\mathrm{a}}$ & $118.5 \pm 3.2^{\mathrm{a}}$ \\
Crude SLSW & $5.7 \pm 0.3^{\mathrm{a}}$ & $114.8 \pm 9.8^{\mathrm{a}}$ \\
EHC solution & $6.3 \pm 0.2^{\mathrm{b}}$ & $129.8 \pm 4.1^{\mathrm{b}}$ \\
\hline
\end{tabular}

the EHC solution. Thus, it was concluded that the adsorptive recovery method is efficient in removing free carbohydrates. Concentration reduction of carbohydrates should reduce the availability of nutrients for several microorganisms, such as some decaying fungi, as we have previously suggested that carbohydrate presence in extracts could result in a worse performance of extracts as potential wood preservatives [20].

The antioxidant tests of the crude SLSW and the EHC solution showed that both have antioxidant activity, but the activity of the EHC solution exceeded that of the crude SLSW. While the antioxidant activity of the crude SLSW was similar-but slightly lower-than those of the references at the highest concentration, the EHC solution proved to be an effective antioxidant and comparable to the references even at half of the total concentration of the SLSW solution. The higher antioxidant activity of EHC compared to SLSW could be related to the higher concentration of phenolics, such as proanthocyanidins, which are known to have antioxidant activity [44] The antioxidant activity of extractives has been suggested to play a role in the decay resistance of wood [45] and to improve the performance of wood preservatives [12]. Thus, these results showed the potential of the compounds in SLSW as additives in wood preservatives formulations. In addition, the high antioxidant activity of EHC solution should be considered for other applications, as antioxidants are often used for other purposes, such as food preservation and additives [46], and are known to reduce health-related risks, such as cancer [47].

The results of the antifungal test showed that neither crude SLSW nor EHC solution was a good antifungal against any of the fungi in the test. None of the tested solutions inhibited the fungi significantly, and, in some casesgenerally at those at higher concentrations -the fungal growth was promoted. When mixed with silvanolin, the antifungal activity of crude SLSW and EHC solution was slightly improved. These findings are similar to the findings from Laks et al. [48] where bark extracts did not work effectively as wood preservatives unless they were combined with copper. Nevertheless, the performance of either SLSW and EHC mixed with silvanolin was not as good as silvanolin by itself. Moreover, the solutions were not effective against all the fungi species. This proved that SLSW reduced the antifungal effectiveness of silvanolin, proving that SLSW and EHC should not be added to commercial preservatives, such as silvanolin, as the performance will not be as good as the preservatives' alone. The reason for the low performance of crude SLSW and EHC solution as antifungals could be related to the low concentration of some constituents that act as fungal inhibitors, such as phenolics [49], stilbenes [25], or flavonoids [50] and the tolerance of fungi to some of them. In addition, the presence of bound carbohydrates (a broad array of possible glucosides) after the adsorptive recovery and purification removing the free carbohydrates could also 
be responsible for the low antifungal activity-and even the growth promotion - of SLSW, as sugars are difficult to separate from phenolics [51] make wood more susceptible to several fungi [52].

The mini-block test showed that 1\% SLSW impregnation did not cause the necessary wood-preserving activity to consider the crude SLSW and EHC solution as potential wood preservatives, even if some of the fungi caused a slight decrease in mass loss compared to controls. We could not find previous reports on the possible use of SLSW as wood preservatives, but it was demonstrated that Scots' pine sapwood impregnated with 5\% crude SLSW lost more mass than the controls when exposed to a decay test with Coniophora puteana for 16 weeks [28]. The results of BarberoLópez et al. [28] and this study indicate a similar trend in mass loss to the results found in the antifungal test, as higher concentrations of crude SLSW resulted in a higher mass loss in the wood specimens. Previous studies found that sometimes, bark extracts do not work as wood preservatives, such as Pinus taeda bark extracts [48]. A higher concentration of sugars in the wood treated with higher concentration of SLSW could be the reason why higher concentrations of this liquid had lower efficacy as a preserving agent for wood, as sugars can promote the growth of fungi [52]. It has been reported that the durability of the wood is not only the function of the presence of bioactive extractives, but other parameters, such as water exclusion efficacy, microdistribution of extractives and suchlike [53]. In addition, tannins' presence in wood is related to the mechanical performance of some wood species, such as chestnut wood [54]. The larger amount of phenols found in EHC solution compared to SLSW could be the reason for the increased Emod of EHC treated wood. However, SLSW did not affect the mechanical properties of wood and the EHC solution caused only a slight increase in the $\mathrm{E}_{\text {mod, }}$, possibly because the concentration of tannins was not high enough in the liquid to cause a relevant increment. Thus, these results indicate that despite containing antifungal constituents, using SLSW as a wood preservative is impossible.

It is also important to note that the ecotoxicity of SLSW needs to be studied. Barbero-López et al. [28] indicated that crude SLSW ecotoxicity was slightly lower than that of Colatan GT10, Quebracho (Schinopsis lorenzii) bark extract, rich in tannins, and much lower than the ecotoxicity of the commercial copper-based wood preservative used as a reference in that study. Further studies are needed to understand whether SLSW ecotoxicity is as low as this first study found, as they contain constituents that are of interest for fields, such as wood preservation, where chemicals with low ecotoxicity are needed to substitute the current preservatives with high ecotoxicity.

Overall, it is important to highlight that despite the lowor negative-antifungal and wood-preserving properties of the crude SLSW and EHC solution, this cheap and abundant liquor contains several constituents of interest to the wood-preserving industry; once purified, it also has high antioxidant activity. It must be highlighted that the concentration of these constituents in Norway spruce bark might vary depending on the felling season [55], storage duration $[43,56]$, and the water temperature used to soak the liquid, as different temperatures will cause variations in the extraction yield of extracts from Norway spruce [57].

It is reasonable to assume that tree genotypes and growth conditions also play a role. Thus, as the concentration of constituents varies significantly in the log soaking water [5], checking the concentration of the constituents in SWSL during different seasons of the year and different wood species to identify these variations is imperative. Thus, while crude SLSW or EHC solutions are not useful wood preservatives, they should be studied as potential raw materials for preservative formulations, as the antioxidant activity of this liquid could complement the wood protection provided by the preservatives $[45,58]$. The purification of SLSW successfully removed a significant part of the free carbohydrates in the liquid but did not improve the performance of the liquid. A mild hydrolytic treatment could be used to cleave the glycosic bonds and remove all carbohydrates before the adsorption step. Isolating individual constituents of SLSW using chromatography and/or liquid-liquid extraction should be studied to understand how they affect fungal growth in wood.

\section{Conclusion}

Despite containing several constituents known as antifungals, it can be concluded that SLSWs are not good wood preservatives. The presence of glucosides or other chemicals that promote fungal growth could be responsible for this. The SLSW performance as antifungals and preservatives did not improve after removing free carbohydrates, but the antioxidant activity got higher. Thus, SLSW should be studied as a source of wood preservatives to provide them with antioxidant activity and improve their performance. In addition, they should be studied for other end uses.

Acknowledgements The authors thank Mr. Tommi Huhtanen for his assistance in the experiments.

Funding Open access funding provided by University of Eastern Finland (UEF) including Kuopio University Hospital. The authors would like to acknowledge the support provided by the Academy of Finland project ECOCIDE 329884 and NIEMI Foundation grants 20190113 and 20200072. Authors would also like to acknowledge the Slovenian Research Agency for supporting program P4-0015. 
Data availability The data will be kept by the authors of this study.

Code availability Not applicable.

\section{Declarations}

Conflict of interest The author declares no conflict of interest in publishing this manuscript.

Open Access This article is licensed under a Creative Commons Attribution 4.0 International License, which permits use, sharing, adaptation, distribution and reproduction in any medium or format, as long as you give appropriate credit to the original author(s) and the source, provide a link to the Creative Commons licence, and indicate if changes were made. The images or other third party material in this article are included in the article's Creative Commons licence, unless indicated otherwise in a credit line to the material. If material is not included in the article's Creative Commons licence and your intended use is not permitted by statutory regulation or exceeds the permitted use, you will need to obtain permission directly from the copyright holder. To view a copy of this licence, visit http://creativecommons.org/licenses/by/4.0/.

\section{References}

1. Rohumaa, A., Yamamoto, A., Hunt, C.G., Frihart, C.R., Hughes, M., Kers, J.: Effect of log soaking and the temperature of peeling on the properties of rotary-cut birch (Betula pendula Roth) veneer bonded with phenol-formaldehyde adhesive. BioResources 11, 5829-5838 (2016)

2. Dupleix, A., Denaud, L.-E., Bleron, L., Marchal, R., Hughes, M.: The effect of log heating temperature on the peeling process and veneer quality: beech, birch, and spruce case studies. Eur. J. Wood Wood Prod. 71, 163-171 (2013)

3. Yamamoto, A., Rohumaa, A., Kontturi, E., Hughes, M., Vuorinen, T.: Chemical characteristics of squeezable sap of hydrothermally treated silver birch logs (Betula pendula): effect of treatment time and the quality of the soaking water in pilot scale experiment. Wood Sci. Technol. 49, 289-302 (2015)

4. Plath, E., Plath, L.: Papierchromatographische Untersuchungen an Dämpfkondensaten von Rotbuche. Holz Roh- Werkst 13, 226-237 (1955)

5. Mayer, I., Koch, G., Puls, J.: Chemical investigations on boiling process waters in face veneer production. Eur. J. Wood Wood Prod. 65, 315-320 (2007)

6. Liu, M., Zhong, H., Ma, E., Liu, R.: Resistance to fungal decay of paraffin wax emulsion/copper azole compound system treated wood. Int. Biodeterior. Biodegrad. 129, 61-66 (2018)

7. Hiemstra, T.F., Bellamy, C.O.C., Hughes, J.H.: Coal tar creosote abuse by vapour inhalation presenting with renal impairment and neurotoxicity: a case report. J. Med Case Rep. 1, 102 (2007)

8. Humar, M.: Protection of the bio-based material. In: Dennis, J., Brischke, C. (Eds.) Performance of Bio-Based Building Materials, pp. 187. Woodhead Publishing, Cambridge (2017)

9. Hawley, L.F., Fleck, L.C., Richards, C.A.: The relation between durability and chemical composition in wood. Ind. Eng. Chem. 16, 699-700 (1924)

10. Harju, A.M., Venäläinen, M., Anttonen, S., Viitanen, H., Kainulainen, P., Saranpää, P., Vapaavuori, E.: Chemical factors affecting the brown-rot decay resistance of Scots pine heartwood. Trees 17, 263-268 (2003)

11. Anttila, A.-K., Pirttilä, A.M., Häggman, H., Harju, A., Venäläinen, M., Haapala, A., Holmbom, B., Julkunen-Tiitto, R.: Condensed conifer tannins as antifungal agents in liquid culture. Holzforschung 67, 825-832 (2013)

12. Broda, M.: Natural compounds for wood protection against fungi-a review. Molecules 25, 3538 (2020)

13. Vek, V., Oven, P., Humar, M.: Phenolic extractives of woundassociated wood of beech and their fungicidal effect. Int. Biodeterior. Biodegrad. 77, 91-97 (2013)

14. Su, Y.-C., Ho, C.-L., Wang, E.I.-C., Chang, S.T.: Antifungal activities and chemical compositions of essential oils from leaves of four eucalypts. Taiwan J. For. Sci. 21, 49-61 (2006)

15. Firouzbehi, F., Efhamisisi, D., Hamzeh, Y., Tarmian, A., Oladi, R.: Pyrolysis acid as sustainable wood preservative against rot fungi. Biofuels Bioprod. Biorefin. 15, 74-84 (2021)

16. Chittenden, C., Singh, T.: Antifungal activity of essential oils against wood degrading fungi and their applications as wood preservatives. Int. Wood Prod. J. 2, 44-48 (2011)

17. Temiz, A., Alma, M.H., Terziev, N., Palanti, S., Feci, E.: Efficiency of bio-oil against wood destroying organisms. J. Biobased Mater. Bioenergy 4, 1-7 (2010)

18. Shiny, K.S., Sundararaj, R., Vijayalakshmi, G.: Potential use of coconut shell pyrolytic oil distillate (CSPOD) as wood protectant against decay fungi. Eur. J. Wood Wood Prod. 76, 767-773 (2018)

19. Vek, V., Balzano, A., Poljanšek, I., Humar, M., Oven, P.: Improving fungal decay resistance of less durable sapwood by impregnation with Scots pine Knotwood and Black locust Heartwood hydrophilic extractives with antifungal or antioxidant properties. Forests 11, 1024 (2020)

20. Barbero-López, A., Monzó-Beltrán, J., Virjamo, V., Akkanen, J., Haapala, A.: Revalorization of coffee silverskin as a potential feedstock for antifungal chemicals in wood preservation. Int. Biodeterior. Biodegrad. 152, 105011 (2020)

21. Mohan, D., Shi, J., Nicholas, D.D., Pittman, C.U., Jr., Steele, P.H., Cooper, J.E.: Fungicidal values of bio-oils and their lignin-rich fractions obtained from wood/bark fast pyrolysis. Chemosphere 71, 456-465 (2008)

22. Barbero-López, A., Hossain, M., Haapala, A.: Antifungal activity of organic acids and their impact on wood decay resistance. Wood Fiber Sci. 52, 410-418 (2020)

23. Bang, K.H., Kim, Y.K., Min, B.S., Na, M.K., Rhee, Y.H., Lee, J.P., Bae, K.H.: Antifungal activity of magnolol and honokiol. Arch. Pharmacal. Res. 23, 46-49 (2000)

24. Apers, S., Vlietinck, A., Pieters, L.: Lignans and neolignans as lead compounds. Phytochem. Rev. 2, 201-217 (2003)

25. Lu, J., Venäläinen, M., Julkunen-Tiitto, R., Harju, A.M.: Stilbene impregnation retards brown-rot decay of Scots pine sapwood. Holzforschung 70, 261-266 (2016)

26. Li, Z.-J., Liu, M., Dawuti, G., Dou, Q., Ma, Y., Liu, H.-G., Aibai, S.: Antifungal activity of gallic acid in vitro and in vivo. Phytother. Res. 31, 1039-1045 (2017)

27. Aziz, N.H., Farag, S.E., Mousa, L.A.A., Abo-Zaid, M.A.: Comparative antibacterial and antifungal effects of some phenolic compounds. Microbios 93, 43-54 (1998)

28. Barbero-López, A., Akkanen, J., Lappalainen, R., Peräniemi, S., Haapala, A.: Bio-based wood preservatives: their efficiency, leaching and ecotoxicity compared to a commercial wood preservative. Sci. Total Environ. 753, 142013 (2021)

29. Hagermann, A.E.: Tannin Handbook. Department of Chemistry \& Biochemistry, Miami University, Oxford. http://www.users.miami oh.edu/hagermae/ (2011)

30. Eisenhuber, K., Krennhuber, K., Steinmüller, V., Jäger, A.: Comparison of different pre-treatment methods for separating hemicellulose from straw during lignocellulose bioethanol production. Energy Proc. 40, 172-181 (2013) 
31. Humar, M., Žlindra, D., Pohleven, F.: Fixation of copper-ethanolamine wood preservatives to Norway spruce sawdust. Acta Chim. Slov. 54, 154-159 (2007)

32. Hayes, D.J.M.: Development of near infrared spectroscopy models for the quantitative prediction of the lignocellulosic components of wet Miscanthus samples. Biores. Technol. 119, 393-405 (2012)

33. Broadhurst, R.B., Jones, W.T.: Analysis of condensed tannins using acidified vanillin. J. Sci. Food Agric. 29, 788-794 (1978)

34. Singleton, V.L., Rossi, J.A.: Colorimetry of total phenolics with phosphomolybdic-phosphotungstic acid reagents. Am. J. Enol. Vitic. 16, 144-158 (1965)

35. Scalbert, A., Monties, B., Janin, G.: Tannins in wood: comparison of different estimation methods. J. Agric. Food Chem. 37, 1324-1329 (1989)

36. Chen, P.-S., Chen, Y.-H., Yeh, T.-F., Chang, S.-T.: Mechanism of decay resistance of heartwood extracts from Acacia confusa against the brown-rot fungus Laetiporus sulphureus. Wood Sci. Technol. 48, 451-465 (2014)

37. Tavčar Benković, E., Žigon, D., Mihailović, V., Petelinc, T., Jamnik, P., Kreft, S.: Identification, in vitro and in vivo antioxidant activity, and gastrointestinal stability of lignans from silver fir (Abies alba) wood extract. J. Wood Chem. Technol. 37, 467-477 (2017)

38. Vek, V., Poljansek, I., Humar, M., Willfor, S., Oven, P.: In vitro inhibition of extractives from knotwood of Scots pine (Pinus sylvestris) and black pine (Pinus nigra) on growth of Schizophyllum commune, Trametes versicolor, Gloeophyllum trabeum and Fibroporia vaillantii. Wood Sci. Technol. 54, 1645-1662 (2020)

39. Raspor, P., Smole-Možina, S., Podjavoršek, J., Pohleven, F., Gogala, N., Nekrep, F.V., Rogelj, I., Hacin, J.: Culture collection of industrial microorganisms (ZIM). Biotehniška fakulteta, Ljubljana (1995)

40. Cushnie, T.P.T., Cushnie, B., Echeverría, J., Fowsantear, W., Thammawat, S., Dodgson, J.L.A., Law, S., Clow, S.M.: Bioprospecting for antibacterial drugs: a multidisciplinary perspective on natural product source material, bioassay selection and avoidable pitfalls. Pharm. Res. 37, 125 (2020)

41. Humar, M., Lesar, B.: Fungicidal properties of individual components of copper-ethanolamine-based wood preservatives. Int. Biodeterior. Biodegrad. 62, 46-50 (2008)

42. Schmidt, O.: Wood and tree fungi: biology, damage, protection, and use, p. 336. Springer, Berlin (2006)

43. Jyske, T., Brännström, H., Sarjala, T., Hellström, J., Halmemies, E., Raitanen, J.-E., Kaseva, J., Lagerquist, L., Eklund, P., Nurmi, J.: Fate of antioxidative compounds within bark during storage: a case of Norway spruce logs. Molecules 25, 4228 (2020)

44. Luximon-Ramma, A., Bahorun, T., Soobrattee, M.A., Arouma, O.I.: Antioxidant activities of phenolic, proanthocyanidin, and flavonoid components in extracts of Cassia fistula. J. Agric. Food Chem. 50, 5042-5047 (2002)

45. Belt, T., Hänninen, T., Rautkari, L.: Antioxidant activity of Scots pine heartwood and knot extractives and implications for resistance to brown rot. Holzforschung 71, 527-534 (2017)

46. Figueroa, J.G., Borrás-Linares, I., Del Pino-García, R., Curiel, J.A., Lozano-Sánchez, J., Segura-Carretero, A.: Functional ingredient from avocado peel: microwave-assisted extraction, characterization and potential applications for the food industry. Food Chem. 352, 129-300 (2021)

47. Sindhi, V., Gupta, V., Sharma, K., Bhatnagar, S., Kumari, R., Dhaka, N.: Potential applications of antioxidants: a review. J. Pharm. Res. 7, 828-835 (2013)

48. Laks, P.E., McKaig, P.A., Hemingway, R.W.: Flavonoid biocides: wood preservatives based on condensed tannins. Holzforschung 42, 299-306 (1988)

49. Xu, D., Deng, Y., Han, T., Jiang, L., Xi, P., Wang, Q., Jiang, Z., Gao, L.: In vitro and in vivo effectiveness of phenolic compounds for the control of postharvest gray mold of table grapes. Postharvest. Biol. Technol. 139, 106-114 (2018)

50. Orhan, D.D., Özçelik, B., Özgen, S., Ergun, F.: Antibacterial, antifungal, and antiviral activities of some flavonoids. Microbiol. Res. 165, 496-504 (2010)

51. Sepperer, T., Hernandez-Ramos, F., Labidi, J., Oostingh, G.J., Bogner, B., Petutschnigg, A., Tondi, G.: Purification of industrial tannin extract through simple solid-liquid extractions. Ind. Crops Prod. 139, 111502 (2019)

52. Schmidt, O., Magel, E., Frühwald, A., Glukhykh, L., Erdt, K., Kaschuro, S.: Influence of sugar and starch content of palm wood on fungal development and prevention of fungal colonization by acid treatment. Holzforschung 70, 783-791 (2016)

53. Meyer-Veltrup, L., Brischke, C., Alfredsen, G., Humar, M., Flæte, P.O., Isaksson, T., Brelid, P.L., Westin, M., Jermer, J.: The combined effect of wetting ability and durability on outdoor performance of wood: development and verification of a new prediction approach. Wood Sci. Technol. 51, 615-637 (2017)

54. Gunduz, G., Aydemir, D., Onat, S.M., Akgun, K.: The effects of tannin and thermal treatment on physical and mechanical properties of laminated chestnut wood composites. BioResources $\mathbf{6}$, 1543-1555 (2011)

55. Jyske, T.M., Suuronen, J.P., Pranovich, A.V., Laakso, T., Watanabe, U., Kuroda, K., Abe, H.: Seasonal variation in formation, structure, and chemical properties of phloem in Picea abies as studied by novel microtechniques. Planta 242, 613-629 (2015)

56. Routa, J., Brännström, H., Anttila, P., Mäkinen, M., Jänis, J., Asikainen, A.: Wood extractives of Finnish pine, spruce and birchavailability and optimal sources of compounds, a literature review. Natural resources and bioeconomy studies 73/2017 (2017). https:// jukuri.luke.fi/bitstream/handle/10024/540829/luke-luobio_73_ 2017.pdf.pdf?sequence $=1$

57. Bianchi, S., Koch, G., Janzon, R., Mayer, I., Saake, B., Pichelin, F.: Hot water extraction of Norway spruce (Picea abies [Karst.]) bark: analyses of the influence of bark aging and process parameters on the extract composition. Holzforschung 70, 619-631 (2016)

58. Schultz, T.P., Nicholas, D.D.: Naturally durable heartwood: evidence for a proposed dual defensive function of the extractives. Phytochemistry 54, 47-52 (2000)

Publisher's Note Springer Nature remains neutral with regard to jurisdictional claims in published maps and institutional affiliations. 


\section{Authors and Affiliations}

Aitor Barbero-López ${ }^{1}\left(\mathbb{D} \cdot\right.$ Viljem Vek $^{2} \cdot$ Ida Poljanšek $^{2} \cdot$ Virpi Virjamo $^{1,3} \cdot$ Yeray Manuel López-Gómez $^{1}$. Tuomo Sainio ${ }^{4} \cdot$ Miha Humar $^{2} \cdot$ Primož Oven $^{2}$. Antti Haapala ${ }^{1}$

1 School of Forest Sciences, University of Eastern Finland, P.O. Box 111, 80101 Joensuu, Finland

2 Department of Wood Science and Technology, Biotechnical Faculty, University of Ljubljana, 1000 Ljubljana, Slovenia
3 Department of Environmental and Biological Sciences, University of Eastern Finland, P.O. Box 111, 80101 Joensuu, Finland

4 School of Engineering Science, Lappeenranta-Lahti University of Technology LUT, 15210 Lahti, Finland 